6 - ORIGINAL ARTICLE

TRANSPLANTATION

\title{
Remote ischemic preconditioning and tacrolimus in the fetal small bowel transplant in mice $^{1}$
}

\author{
Ricardo José Morello', Marcia Kiyomi Koike ${ }^{\mathrm{II}}$, Marcos de Souza AbrahãoI, Karen Ruggeri Saad ${ }^{\mathrm{III}}$, Paulo Fernandes Saad ${ }^{\mathrm{III}}$, \\ Edna Frasson de Souza Montero ${ }^{\mathrm{IV}}$
}

DOI: http://dx.doi.org/10.1590/S0102-865020160100000006

${ }^{I} \mathrm{PhD}$, Operative Technique and Experimental Surgery Division, Medical School, Universidade Federal de São Paulo (UNIFESP), Brazil. Technical procedures, acquisition of data, manuscript writing.

IIPhD, Laboratory of Emergency Medicine - LIM-51, Faculty of Medicine (FM), Universidade de São Paulo (USP), Brazil. Interpretation of data, histopathological examinations, statistical analysis, manuscript writing.

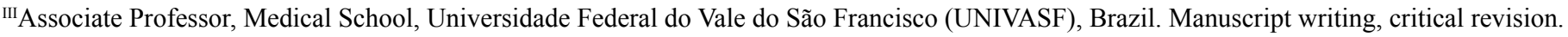

${ }^{\mathrm{IV}}$ Associate Professor, Surgical Physiopathology Laboratory (LIM-62), FMUSP. Affiliate Professor, Operative Technique and Experimental Surgery Division, Medical School, UNIFESP, Sao Paulo-SP, Brazil. Conception, intellectual and scientific content of the study; critical revision; final approval.

\section{ABSTRACT}

PURPOSE: To evaluate the effect of remote ischemic preconditioning (IPC-R) in the fetal small bowel transplantation model.

METHODS: Two groups were constituted: The Isogenic transplant (ISO, C57BL/6 mice, n=24) and the allogenic transplant (ALO, $\mathrm{BALB} / \mathrm{c}$ mice, $\mathrm{n}=24)$. In each group, the animals were distributed with and without IPC-R. It was obtained the following subgroups: Tx, IPC-R, Fk, IPC-Fk, in both strains. Intestinal grafts were stained with hematoxylin and eosin and immunohistochemically.

RESULTS: The graft development evaluation in ISO group showed that IPC-R reduced the development compared with ISO-Tx (5.2 \pm 0.4 vs 9.0 \pm 0.8$)$ and IPC-R-Fk increased the graft development compared with IPC-R (11.2 \pm 0.7 and 10.2 \pm 0.8$)$. In ALO group, IPC-Fk increased the development compared with ALO-Tx and ALO with IPC-R (6.0 $\pm 0.8,9.0 \pm 1.2,0.0 \pm 0.0,0.5 \pm 0.3)$. The PCNA expression was increased in ISO group treated with Fk and IPC-R compared to other groups (12.2 \pm 0.8 vs Tx: 8.8 \pm 0.9 , IPC-R: 8.0 \pm 0.4 and Fk: 9.0 \pm 0.6$)$. The graft rejection was lower in groups treated with IPC-R (-18\%), Fk (-68\%) or both (-61\%) compared with ALO-Tx. CONCLUSION: Remote ischemic preconditioning showed benefic effect even associate with Tacrolimus on the development and acute rejection of the fetal small bowel graft in the Isogenic and Allogenic transplants.

Key words: Fetal Tissue Transplantation. Small Intestine. Tacrolimus. Ischemic Preconditioning. Mice. 


\section{Introduction}

Intestinal transplantation has become an accepted therapy for intestinal disease in patients who require total parenteral nutrition ${ }^{1}$. Although the results of small bowel transplantation have improved during the past few years, rejection, infection, preservation, and reperfusion injury continues to be a major obstacle. In transplantation surgery or complex trauma, the interruption and restoration of blood flow to organs and tissues, cause a cascade of events known as ischemia-reperfusion (IR) syndrome. The generation of free radicals during this event promotes cellular and membrane alterations causing cell death ${ }^{2}$.

Some protection strategies have been used for the preservation amongst of the tissues, them the ischemic preconditioning (IPC). The IPC is a surgical alternative that employs short cycles of ischemia followed by reperfusion, previously to a sustained ischemia ${ }^{2}$.

Murry et $a l .^{3}$, using the myocardium muscle of dogs, could register the protective effect of IPC through a number of experiments, when the term ischemic preconditioning was definitively divulged. In the small intestine dysfunction observed after sustained warm ischemia was prevented if preconditioning was carried out before the ischemia ${ }^{4}$. The mechanism of remote preconditioning is not limited to one organ system either: Freitas et al. ${ }^{5}$ noted that maternal IPC protected the colonic mucosa of neonatal rats subjected to hypoxia and reoxygenation, reducing the morphological changes and the inflammatory response. In another study ${ }^{6}$, the authors showed that the IPC protected against ischemia-reperfusion injury in remote lung intestinal ischemiareperfusion on or hepatic model with acute diabetes.

Considering that the IPC protects the gut in hypothermic condition improving post- transplantation ${ }^{7}$; the mechanism involves R-IPC different paths of action in relation to IPC, and that in a previous study in our lab, showed increased IPC-R cell proliferation and neovascularization of the ovarian graft $^{8}$; it was decided to verify the role of intestinal transplantation IPC-R and its impact on intestinal development and in the process of acute allogeneic rejection.

\section{Methods}

All animals were handled according to the ethical principles of laboratory animal care (law 11.794, October 8, 2008), which governs the ethical use of animals for experimentation and followed the guidelines by the Research Ethics Committee of the UNIFESP (protocol $n^{\circ}$ 0864/08).

It was used four female $\mathrm{C} 57 \mathrm{BL} / 6$ mice on the $18^{\text {th }}$ day of pregnancy submitted or not to R-IPC, $24 \mathrm{BALB} / \mathrm{c}$ adult male mice and $24 \mathrm{C} 57 \mathrm{BL} / 6$ adult male mice.

The females were weighed and then anesthetized using intramuscular (IM) injection of ketamine $(80 \mathrm{mg} / \mathrm{kg})$ and xylazine $(10 \mathrm{mg} / \mathrm{kg})$ and maintained on a heated pad (Gaymar T/Pump) at $37^{\circ} \mathrm{C}$. Using a clean technique, the IPC-R was accomplished by occlusion of the left femoral artery during 10 minutes, followed for similar time of reperfusion, following laparotomy, hysterotomy was accomplished, and a transverse laparotomy was performed in the fetus to expose the small intestine, using microsurgical x16 magnification. All intestines were harvested, cleaned from their mesentery, and divided into segments of $1-\mathrm{cm}$ length. Nonvascularized small bowel grafts were immediately transplanted, in the space between the straight-abdominal muscle and pre-peritoneal of the recipients to half centimeter of the xiphoid appendix, left of the medium line. After the transplant, the abdominal wall was closed with prolene 7-0 sutures.

The immunosuppressant used was Tacrolimus (Fk, $5 \mathrm{mg} /$ $\mathrm{kg}$ /day v.o.) and then, it was obtained the following subgroups: ALO-Tx, ALO-IPC, ALO-Fk, ALO-IPC-Fk, ISO-Tx, ISO-IPC, ISO-Fk and ISO-IPC-Fk.

After seven days' follow-up, the graft of small bowel was removed surgically and the animals were sacrificed by lethal dose of anesthetic compound.

\section{Histomorphological evaluation}

The sample was fixed in buffered formalin solution for 12 hours and embedded in paraffin and stained by hematoxylin-eosin and periodic Acid-Schiff complemented with Alcian Blue staining (PAS / Alcian Blue).

For morphological analysis of the development process and/or graft rejection was used the score proposed by Auber et al. ${ }^{9}$.

For morphometric study was performed under microscope light coupled to a computerized imaging and program Image J software.

\section{Immunohistochemical analysis}

For immunohistochemistry, $4 \mathrm{uM}$ slides sections treated with 3- aminopropyltriethoxysilane were used. The sections were deparaffinized in an oven at $60{ }^{\circ} \mathrm{C}$ for 12 hours, followed by xylol bath at room temperature for 30 minutes.

The slides were hydrated in ethanol baths with decreasing concentrations, washed in water and kept in phosphate buffered saline (PBS). Antigen retrieval was performed with Pascal pot use, cap 0.01 molar sodium citrate, $\mathrm{pH}$ 6.0, for 5 minutes, then cooling to room temperature for 20 minutes. Blockage of endogenous 
peroxidase was performed with hydrogen peroxide solution (10 vol), 5 min for 4 cycles followed by rinsing with tap water and distilled water.

For blocking nonspecific sites, sections were incubated in $1 \%$ solution of bovine serum albumin in PBS for 15 minutes, discarding the excess after this time. The primary antibody was diluted in PBS solution at a dilution of 1: 5000 for polyclonal anti-antigen mouse human proliferation (PCNA, Cell Signaling Technology), and incubated on the sections in a moist chamber for 18 hours at $4^{\circ} \mathrm{C}$. Then, the sections were washed in PBS and incubated with biotinylated secondary antibody Advance kit (Dako) followed by incubation with streptavidin-biotin-peroxidase complex of the same kit. Incubations were performed in a moist chamber at room temperature for 15 minutes followed by rinses in PBS.

The development was performed with $1 \%$ solution of 3,3'-diaminobenzidine (Sigma) and hydrogen peroxide in PBS for $5 \mathrm{~min}$ at room temperature, followed by washing in water. The counterstaining was performed with Harris hematoxylin for 1 minute, followed by extensive washing in running water. After drying diafanization, the slides were mounted with Entellan resin (Sigma).

The analysis of immunohistochemistry was performed throughout fetal gut graft considering the villi crypt intestinal epithelium and muscle layer. Employed is a semi quantitative evaluation by scoring positively labeled cells second location criteria for the antibodies used.

\section{Statistical analysis}

The data were analyzed using the SigmaStat statistical program, version 3.1 (Systat Software, San Jose, CA). The analysis of variance (ANOVA and ANOVA on ranks), supplemented by test Student-Newman-Keuls or a Dunn, was used for the remainder of statistical analysis, which included the development score data, rejection and cell proliferation score. Difference was considered statistically significant when $\mathrm{P}<0.05$.

\section{Results}

In relation to assessment of the development of the fetal small bowel graft in isogenic transplantation after seven days of follow-up, the results showed that the development was significantly lower in the ISO-IPC group compared to the ISO-Tx group. The ISO-FK group and ISO IPC-FK group showed higher scores development of the graft as compared to ISO-IPC group (Figure 1).

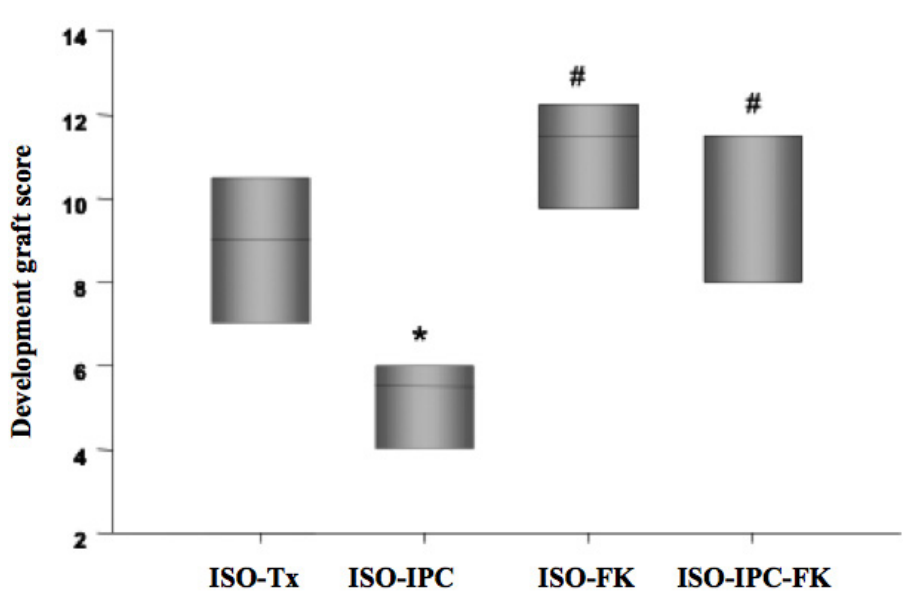

FIGURE 1 - Development of the fetal small bowel graft in isogenic transplantation (ISO) after seven days of follow-up. ISO-Tx transplanted without treatment; IPC, transplanted submitted prior to remote ischemic preconditioning; Fk transplanted treated with Tacrolimus. ${ }^{*} \mathrm{P}<0.05$ vs. ISO-Tx; \#, P $<0.05$ vs ISO-IPC.

Already in allogeneic transplant group, the evaluation of the fetal small bowel graft showed that the development was significantly higher in the groups treated with tacrolimus when compared to ALO-Tx or ALO-IPC group. The IPC-R did not change significantly the development of graft in multiple comparison groups (Figure 2). However, the comparison between two independent groups, ALO-ALO and Fk-Fk-IPC, significance was observed $(p=0.035)$ to the beneficial effect of IPC-R in terms of development score.

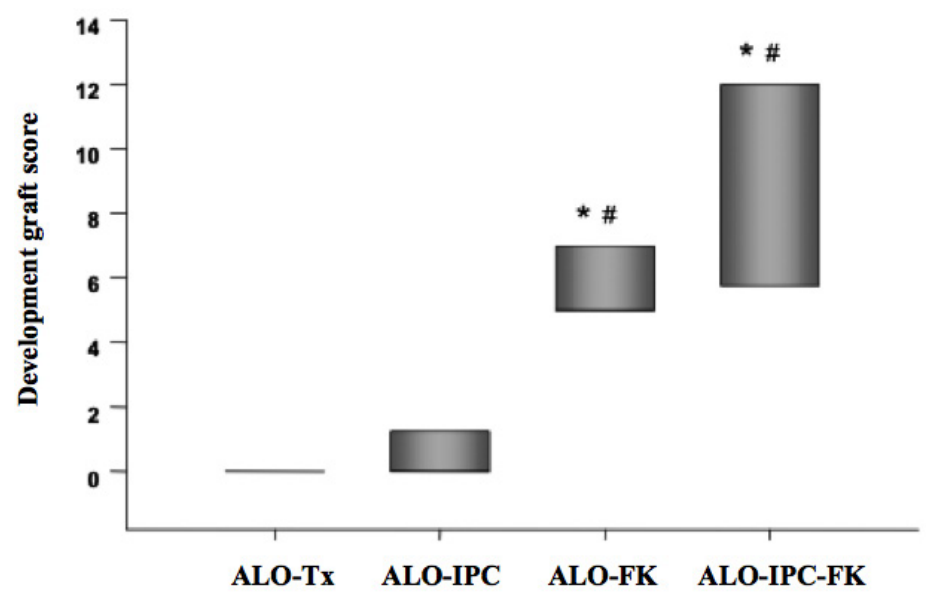

FIGURE 2 - Development of the fetal small bowel graft in allogeneic transplantation (ALO) after seven days of follow-up. ALO-Tx, transplanted without treatment; IPC, transplanted submitted prior to remote ischemic preconditioning; Fk transplanted treated with Tacrolimus. ${ }^{*} \mathrm{P}<0.05$ vs. ALO-Tx; \#P $<0.05$ vs ALO IPC.

The evaluation of cellular proliferation in the isogenic transplantation group showed that the combination of the IPC-R and treatment with Tacrolimus promoted intense proliferation when compared to the other subgroups ( $12.2 \pm 0.8$ vs Tx: $8.8 \pm 0.9$, IPC-R,: $8.0 \pm 0.4$ e Fk: $9.0 \pm 0.6$ ) (Figure 3). The evaluation of the 
cellular proliferation in allogeneic transplantation group showed no differences between subgroups. Similarly, there was not difference between cell proliferation when compared subgroups of allogeneic and isogenic transplants $(\mathrm{p}=0.28)$.
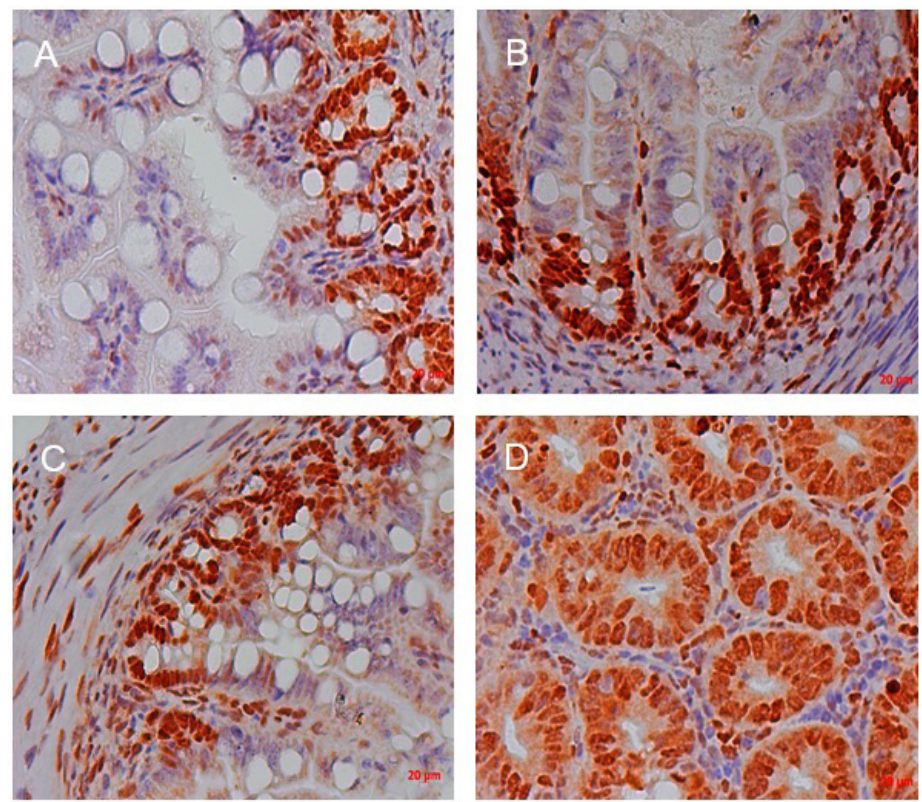

FIGURE 3 - Photomicrograph of the isogenic fetal small bowel graft after seven days of follow-up marked by immunohistochemistry with anti-PCNA antibody. In A, ISO-Tx group; B: ISO-IPC group; C: ISOFk group; and D: ISO-Fk-IPC group. Can be observed numerous cryptic positively stained cells stained brown (x400).

The assessments of rejection of fetal intestine graft isogenic transplantation showed that there was no rejection. Already in the evaluation of rejection of fetal intestine graft in allogeneic transplantation, the results show that there was less rejection in grafts undergone the treatments. The IPC-R and Tacrolimus reduced rejection compared to ALO-Tx group. When associated therapeutic, no synergism or antagonism, which maintained the reduction of acute rejection (Figure 4).

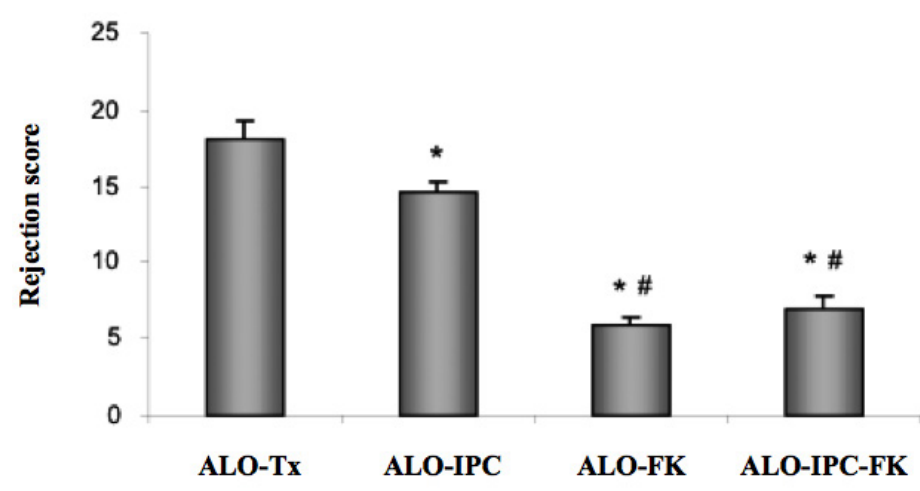

FIGURE 4 - Rejection of fetal small bowel graft in allogeneic transplantation (ALO) after seven days of follow-up. ALO-Tx transplanted without treatment; IPC, transplanted submitted prior to IPC-R; FK transplanted treated with Tacrolimus. ${ }^{*} \mathrm{P}<0.05$ vs. ALO-Tx; $\# \mathrm{P}<0.05$ vs ALO IPC.

\section{Discussion}

This study showed that the IPC-R interferes with the development process and acute rejection of fetal small bowel graft. In the isogenic grafts, this strategy proved beneficial effect when added to tacrolimus treatment, in which there was the highest score development of the graft, as evidenced by increased cell proliferation. Similarly, in allogeneic grafts treated with Tacrolimus, IPC-R has promoted increased development and significant reduction in rejection.

The IPC has an important action in the attenuation of IR lesion and has the advantage of its possibility of use in the current surgical period, with no need of additional surgical procedures, and with no collateral effects from the use of drugs applied to raise the tissue viability. The association of this strategy with Tacrolimus demonstrated additional advantage, since this immunosuppressive drug is related to increased post-transplant survival ${ }^{10}$.

The role of IPC in reducing ischemic injury has been widely documented in a range of tissues, including IR injury of the small intestine ${ }^{11-16}$. A recent study shows that Ischemic preconditioning increased the intestinal stem cell activities in the intestinal crypts in mice ${ }^{17}$.

In this study, the strategy of preconditioning used was 10 minuts of ischemia and the same time for reperfusion. Similarly, Sola et al. ${ }^{7}$, using an experimental model in the study of intestinal transplantation in rats, achieved preconditioning with an ischemic interval of 10 minutes followed by reperfusion of 10 minutes. These results suggest that there is superiority of tissue protection when the IPC strategy in that way.

The graft development score described by Auber et al. ${ }^{9}$, it considers the presence of digestive epithelium, villi, crypts, muscular layer and importance of the mucous secretion. The damage observed in the development score promoted by R-IPC in isogenic grafts can be due to the cystic dilation of the graft, consequent of expressive mucus accumulation inside the of the intestinal light, due to the increase of globet cells, promoting larger amount of secretion committing the aspect of the villi in the mucous membrane, resulting in smaller score of development. Conditions of cystic dilation, as it happened in this group, refers to underestimated score.

The contribution of this research was the beneficial effect of IPC-R on the transplanted intestine, both isogenic as allogeneic. These effects evidenced bowel transplantation model are novel and extremely important since it can make effective contributions to understanding the development of post-operative intestinal graft. 


\section{Conclusions}

Remote ischemic preconditioning showed benefic effect even associate with Tacrolimus on the development and acute rejection of the fetal small bowel graft in the Isogenic and Allogenic transplants, increasing the cellular proliferation in isogenic trnasplants. In the Allogeneic transplant, it increased the development of the graft, it reduced the degree of acute rejection without Immunosuppression, however it didn’t present synergic effect with the immunosuppression.

\section{References}

1. Pironi L, Joly F, Forbes A, Colomb V, Lyszkowska M, Baxter J, Gabe S, Hébuterne X, Gambarara M, Gottrand F, Cuerda C, Thul P, Messing B, Goulet O, Staun M, Van Gossum A; Home Artificial Nutrition \& Chronic Intestinal Failure Working Group of the European Society for Clinical Nutrition and Metabolism (ESPEN). Long-term follow-up of patients on home parenteral nutrition in Europe: implications for intestinal transplantation. Gut. 2011 Jan;60(1):17-25. doi: 10.1136/gut.2010.223255.

2. Mallick IH, Yang W, Winslet MC, Seifalian AM. Ischemiareperfusion injury of the intestine and protective strategies against injury. Dig Dis Sci. 2004 Sep;49(9):1359-77. Review. PMID: 15481305 .

3. Murry CE, Jennings RB, Reimer KA. Preconditioning with ischemia: a delay of lethal cell injury in ischemic myocardium. Circulation. 1986 Nov;74(5):1124-36. PMID: 3769170.

4. Taha MO, Miranda-Ferreira R, Chang AC, Rodrigues AM, Fonseca IS, Toral LB, Cardoso MR, Simões MJ, Oliveira-Junior IS, Monteiro HP, Fagundes DJ, Taha NS, Caricati-Neto A. Effect of ischemic preconditioning on injuries caused by ischemia and reperfusion in rat intestine. Transplant Proc. 2012 Oct;44(8):23048. doi: 10.1016/j.transproceed.2012.07.056.

5. Freitas MA, Gomes Rde O, Soares BL, Artigiani Neto R, Montero EF, Martins JL. Effects of maternal ischemic preconditioning in the colon of newborn rats submitted to hypoxia-reoxygenation insult. Acta Cir Bras. 2014 Jul;29(7):438-44. PMID: 25054874.

6. Thomaz Neto FJ, Koike MK, Abrahão Mde S, Carillo Neto F, Pereira RK, Machado JL, Montero EF. Ischemic preconditioning attenuates remote pulmonary inflammatory infiltration of diabetic rats with an intestinal and hepatic ischemia-reperfusion injury. Acta Cir Bras. 2013 Mar;28(3):174-8. PMID: 23503857.

7. Sola A, De Oca J, González R, Prats N, Roselló-Catafau J, Gelpí E, Jaurrieta E, Hotter G. Protective effect of ischemic preconditioning on cold preservation and reperfusion injury associated with rat intestinal transplantation. Ann Surg. 2001 Jul;234(1):98-106. PMID: 11420489 .

8. Damous LL, Silva SM, Simões RS, Morello RJ, Carbonel AP, Simões MJ, Montero EF. Remote ischemic preconditioning on neovascularization and follicle viability on ovary autotransplantation in rats. Transplant Proc. 2008 Apr;40(3):861-4. doi: 10.1016/j. transproceed.2008.02.065.
9. Auber F, Cerf-Bensussan N, Cavazzana-Calvo M, Fauveau Brousse N, Fischer A, Révillon Y, Sarnacki S. Prévention du rejet d'allogreffe intestinalle par des anticorps antimolécules d'adhésion dans un modèle murin. Chirurgie. 1998 123:122-30.

10. Grant D, Abu-Elmagd K, Mazariegos G, Vianna R, Langnas A, Mangus R, Farmer DG, Lacaille F, Iyer K, Fishbein T on behalf of the Intestinal Transplant Association. Intestinal transplant registry report: global activity and trends. Am J Transplant. 2015 15:210-9. doi: 10.1111/ajt.12979.

11. Erling Junior N, Montero EF, Sannomiya P, Poli-de-Figueiredo LF. Local and remote ischemic preconditioning protect against intestinal ischemic/reperfusion injury after supraceliac aortic clamping. Clinics (Sao Paulo). 2013 Dec;68(12):1548-54. doi: 10.6061/ clinics/2013(12)12.

12. Saeki I, Matsuura T, Hayashida M, Taguchi T. Ischemic preconditioning and remote ischemic preconditioning have protective effect against cold ischemia-reperfusion injury of rat small intestine. Pediatr Surg Int. 2011 Aug;27(8):857-62 doi: 10.1007/s00383-010-2810-3.

13. Neves J de S, Abrahão M de S, Salzedas Netto AA, Montero EF de S, Gonzalez AM. Effects of ischemic preconditioning associated to different preservation solutions in protecting the intestinal graft. Acta Cir Bras. 2011 26(5):396-403. PMID: 21952665.

14. Moore-Olufemi SD, Kozar RA, Moore FA, Sato N, Hassoun HT, Cox CS Jr, Kone BC. Ischemic preconditioning protects against gut dysfunction and mucosal injury after ischemia/reperfusion injury. Shock. 2005 Mar;23(3):258-63. PMID: 15718925.

15. Aksöyek S, Cinel I, Avlan D, Cinel L, Oztürk C, Gürbüz P, Nayci A, Oral U. Intestinal ischemic preconditioning protects the intestine and reduces bacterial translocation. Shock. 2002 Nov; 18(5):476-80. PMID: 12412630.

16. Vlasov TD, Smirnov DA, Nutfullina GM. Preconditioning of the small intestine to ischemia in rats. Neurosci Behav Physiol. 2002 Jul-Aug;32(4):449-53. PMID: 12243268.

17. Chen Y, Lee SH, Tsai YH, Tseng SH. Ischemic preconditioning increased the intestinal stem cell activities in the intestinal crypts in mice. J Surg Res. 2014 Mar;187(1):85-93. doi: 10.1016/j. jss.2013.10.001

\section{Correspondence:}

Karen Ruggeri Saad

Rua Michelangelo, casa 02 Cond. Portal das Águas

56332495 Petrolina - PE Brasil

karenruggeri@gmail.com

Received: Jun 20, 2016

Review: Aug 22, 2016

Accepted: Sep 21, 2016

Conflict of interest: none

Financial source: none

${ }^{1}$ Research performed at Operative Technique and Experimental Surgery Division, Medical School, Universidade Federal de São Paulo (UNIFESP), Brazil. Part of PhD degree thesis, Postgraduate Program in Experimental Surgery. Tutor: Profa. Dra. Edna Frasson de Souza Montero. 